\title{
Optimal Physics Parameterization Scheme Combination of the Weather Research and Forecasting Model for Seasonal Precipitation Simulation over Ghana
}

\author{
Richard Yao Kuma Agyeman, ${ }^{1}$ Thompson Annor, ${ }^{2}$ Benjamin Lamptey, ${ }^{3}$ \\ Emmanuel Quansah, ${ }^{2}$ Jacob Agyekum, ${ }^{2}$ and Sampson Adu Tieku ${ }^{4}$ \\ ${ }^{1}$ Numerical Weather Prediction Unit, Ghana Meteorological Agency (GMet), Accra, Ghana \\ ${ }^{2}$ Department of Physics, Kwame Nkrumah University of Science and Technology (KNUST), Kumasi, Ghana \\ ${ }^{3}$ African Centre of Meteorological Applications for Development (ACMAD), Niamey, Niger \\ ${ }^{4}$ Ghana Meteorological Agency (GMet), Kumasi Airport Office, Kumasi, Ghana \\ Correspondence should be addressed to Richard Yao Kuma Agyeman; richmet06@gmail.com
}

Received 18 June 2017; Revised 30 August 2017; Accepted 26 September 2017; Published 6 December 2017

Academic Editor: Jing-Jia Luo

Copyright (c) 2017 Richard Yao Kuma Agyeman et al. This is an open access article distributed under the Creative Commons Attribution License, which permits unrestricted use, distribution, and reproduction in any medium, provided the original work is properly cited.

\begin{abstract}
Seasonal predictions of precipitation, among others, are important to help mitigate the effects of drought and floods on agriculture, hydropower generation, disasters, and many more. This work seeks to obtain a suitable combination of physics schemes of the Weather Research and Forecasting (WRF) model for seasonal precipitation simulation over Ghana. Using the ERA-Interim reanalysis as forcing data, simulation experiments spanning eight months (from April to November) were performed for two different years: a dry year (2001) and a wet year (2008). A double nested approach was used with the outer domain at $50 \mathrm{~km}$ resolution covering West Africa and the inner domain covering Ghana at $10 \mathrm{~km}$ resolution. The results suggest that the WRF model generally overestimated the observed precipitation by a mean value between $3 \%$ and $64 \%$ for both years. Most of the scheme combinations overestimated (underestimated) precipitation over coastal (northern) zones of Ghana for both years but estimated precipitation reasonably well over forest and transitional zones. On the whole, the combination of WRF Single-Moment 6-Class Microphysics Scheme, GrellDevenyi Ensemble Cumulus Scheme, and Asymmetric Convective Model Planetary Boundary Layer Scheme simulated the best temporal pattern and temporal variability with the least relative bias for both years and therefore is recommended for Ghana.
\end{abstract}

\section{Introduction}

A large percentage of Ghanaians are into agriculture but the increasing unreliable rainfall patterns (in both amount and frequency) are changing growing seasons over the agroecological zones which is impacting heavily on this sector of the economy. The changes in rainfall could be due to climate change [1]. Hydroelectric power supply is another sector that is affected by the changes in precipitation pattern. This is because significant drop in water level in the Volta Lake results in a decline in power generation, leading to the use of thermal energy powered by natural gas and crude oil which is more expensive. This results in rising prices of electrical power, which affects industrial productivity and socioeconomic development. Tall et al. [2] noted that only a mere $2 \%$ of the total cultivated land in West Africa is irrigated, while the remaining $98 \%$ is rain fed. This is an indication of how heavily agriculturalists in the West African subregion rely on rainfall.

Troccoli et al. [3] noted that seasonal to annual predictions of precipitation are useful to many whose activities are influenced in some manner by climate variability and climate change. Appropriate decisions regarding irrigation and fertilization, hydropower generation, dams for irrigation, and disaster control, among others, are all dependent on reliable estimates of monthly and seasonal precipitation amounts [4].

Having reliable seasonal forecasts of rainfall over Ghana using a regional climate model will go a long way to aid 
TABLE 1: Summary of physics parameterization scheme categories and the options used in this study. Two options each from microphysics, cumulus scheme, and planetary boundary layer schemes are used, while one option from each of the remaining physics schemes was employed here.

\begin{tabular}{|c|c|c|c|c|}
\hline Scheme name & Category & Abbreviation & Option number & References \\
\hline $\begin{array}{l}\text { WRF Single-Moment } \\
\text { 5-Class Scheme }\end{array}$ & $\begin{array}{c}\text { Microphysics Scheme } \\
\text { (MPS) }\end{array}$ & WSM5 & 4 & {$[10]$} \\
\hline $\begin{array}{l}\text { WRF Single-Moment } \\
\text { 6-Class Scheme }\end{array}$ & $\begin{array}{c}\text { Microphysics Scheme } \\
\text { (MPS) }\end{array}$ & WSM6 & 6 & {$[11]$} \\
\hline Betts-Miller-Janjic & $\begin{array}{c}\text { Cumulus Scheme } \\
\text { (CUS) }\end{array}$ & BMJ & 2 & {$[12,13]$} \\
\hline $\begin{array}{l}\text { Grell-Devenyi } \\
\text { Ensemble scheme }\end{array}$ & $\begin{array}{l}\text { Cumulus } \\
\text { (CUS) }\end{array}$ & GD & 93 & {$[14]$} \\
\hline $\begin{array}{l}\text { Yonsei University } \\
\text { Scheme }\end{array}$ & $\begin{array}{l}\text { Planetary Boundary } \\
\text { Layer Scheme (PBL) }\end{array}$ & YSU & 1 & {$[15]$} \\
\hline $\begin{array}{l}\text { Asymmetrical } \\
\text { Convective Model }\end{array}$ & $\begin{array}{l}\text { Planetary Boundary } \\
\text { Layer Scheme (PBL) }\end{array}$ & ACM2 & 7 & {$[16,17]$} \\
\hline Unified Noah Model & $\begin{array}{l}\text { Land Surface Model } \\
\text { (LSM) }\end{array}$ & UNM & 2 & {$[18]$} \\
\hline Revised MM5 & $\begin{array}{c}\text { Surface Layer Scheme } \\
\text { (SLC) }\end{array}$ & MM5 & 1 & [19] \\
\hline Rapid Radiative Transfer Model & $\begin{array}{c}\text { Longwave Radiation } \\
\text { (LWR) }\end{array}$ & RRTM & 1 & {$[20]$} \\
\hline Dudhia Scheme & $\begin{array}{c}\text { Shortwave Radiation } \\
\text { (SWR) }\end{array}$ & DS & 1 & {$[21]$} \\
\hline
\end{tabular}

planning and hence reduce the harsh effects of extreme rainfall that impacts agriculture, industry, and domestic usage among others.

The Weather Research and Forecasting (WRF) model has gained wide recognition in mesoscale weather and climate research and forecasting. Recent studies have shown that the WRF model has good potential in handling rainfall features like timing of rainfall, location, evolution, and a good representation of the West African monsoon (WAM) among others [5-7]. Yuan et al. [8] noted a reduction of wet bias of mean seasonal precipitation from Climate Forecast System (CFS) prediction by up to $71 \%$ increase in pattern correlation and a decrease in errors up to $33 \%$.

Díez et al. [9] downscaling ERA-Interim data for seasonal precipitation forecast observed that both statistical and dynamical downscaling approaches performed well depending on the season and on the geographical location. Moreover, they noticed that both methods can be used in combination to produce the best skill scores in some cases.

This work aims to determine the combination of physics parameterization schemes in the WRF model that best simulate seasonal precipitation. In the current study, the rainy seasons of the years 2001 (dry) and 2008 (wet) are simulated using ERA-Interim as forcing data to the model. The intention is to help provide timely and reliable seasonal precipitation forecast over Ghana using limited area dynamical downscaling approach.

\section{Materials and Methods}

2.1. Large-Scale General Circulation Forcing Data. The third generation of the European Centre for Medium-Range Weather Forecast (ECMWF) reanalysis forcing data, the
ERA-Interim as described by Dee et al. [22], is used for this work. The ERA-Interim driving data consists of merged assimilated and observational fields at four time steps per day with spatial resolution of 60 vertical levels and the model top at $10 \mathrm{~Pa}$, having a Gaussian grid with approximately $79 \mathrm{~km}$ horizontal spacing for surface [22].

2.2. The WRF Model. The WRF model is an atmospheric model for weather forecasting and regional climate modeling which is suitable for use in a broad range of applications across scales ranging from meters to thousands of kilometers, including idealized simulations, parameterization research, regional climate research, and data assimilation research [23]. Thus, WRF is suitable for dynamic downscaling. The version 3.6.1 was used in this study.

2.2.1. Model Physics. Global climate models (GCMs) have limited skill in simulating the complex and local climate features due to their coarse resolution and their outputs cannot provide reliable information on precipitation forecast. Downscaling GCM outputs is usually employed to provide fine resolution or point-scale information required for any meaningful assessment on small scales. This is usually done dynamically by employing a regional climate model (RCM) with the appropriate physical parameterization schemes to resolve finer and detailed features which are poorly resolved by GCMs [24].

The Weather Research and Forecasting model has a range of physics schemes as contained in Skamarock et al. [23]. The accuracy of any model-generated estimates naturally depends on the quality of the model physics [22]. Table 1 shows the major categories of physics parameterization schemes and the 
TABLE 2: Seven different WRF parameterizations scheme combinations or configurations (Confs) used for the simulations.

\begin{tabular}{llllllrr}
\hline Conf. & MPS & CUS & PBL & LSM & SWR & LWR & SLC \\
\hline Conf1 & WSM6 & BMJ & YSU & UNM & DS & RRTM \\
Conf2 & WSM6 & BMJ & ACM2 & UNM & DS & RRTM & MM5 \\
Conf3 & WSM5 & GD & YSU & UNM & DS & RRTM \\
Conf4 & WSM5 & BMJ & ACM2 & UNM & DS & RRTM \\
Conf5 & WSM6 & GD & YSU & UNM & DS & RRTM \\
Conf6 & WSM6 & GD & ACM2 & UNM & DS & RRTM \\
Conf7 & WSM5 & BMJ & YSU & UNM & DS & RRTM & MM5 \\
\hline
\end{tabular}

various options from each category, while Table 2 shows their combination employed in this study.

The Ghana Meteorological Agency (GMet) runs WRF model for a three-day weather forecast and employs Conf1 (WSM6, BMJ, and YSU) scheme combination. For a longterm high resolution regional climate simulations, Annor et al. [25] used WSM5, GD, and ACM2 to simulate precipitation over the Volta basin in a climate mode. The GMet and Annor et al. [25] configurations were tested separately and also combined in the quest for a suitable combination of schemes for seasonal prediction of precipitation over Ghana.

2.3. Rainfall Pattern over Ghana. Ghana experiences its rainfall season mainly from April through November [26] which depends on several factors. One such factor is the phase of El Niño-Southern Oscillation (ENSO), namely, El Niño and La Nina. Over Ghana, El Niño results in reduced rainfall, while La Nina years result in a good rainfall season [26]. Rainfall over the country is on a decreasing trend from 1960 to recent years [26]. Sea surface temperatures (SSTs) [27, 28], African Easterly Jet (AEJ), African Easterly Wave (AEW), and Tropical Easterly Jet (TEJ) [29], among others, are known to have influence on the performance of the rainy season over West Africa. Therefore, for a model to simulate precipitation over this region reasonably well, it should be able to simulate these features which will in turn impact the skill of the model.

The Oceanic Niño Index (ONI), 3-month running mean of Extended Reconstructed Sea Surface Temperature (ERSST.v4) anomalies in the Niño 3.4 region from the US Climate Prediction Center (CPC): http://www.cpc.ncep .noaa.gov/products/analysis_monitoring/ensostuff/ensoyears .shtml, shows that 2008 was a La Nina year and it is not surprising that it had much rains as shown in Figure 1.

From Figure 1, it is seen that 2001 received the least amount of rainfall, while 2008 received the most. 2001 and 2008 therefore are used as the dry and wet years, respectively. This period (2000-2010) is chosen since this study is looking at seasonal forecast for the near future and therefore the study focuses on a near current period for the simulations.

2.3.1. Set-Up of $A R W$ for Ghana. To account for large-scale systems which affect and control precipitation over Ghana, a larger domain is created covering $28^{\circ} \mathrm{W}-22^{\circ} \mathrm{E}, 13^{\circ} \mathrm{S}-32^{\circ} \mathrm{N}$, Figure 2(a). This is done also to move the direct effect of boundary conditions far from the region of study.

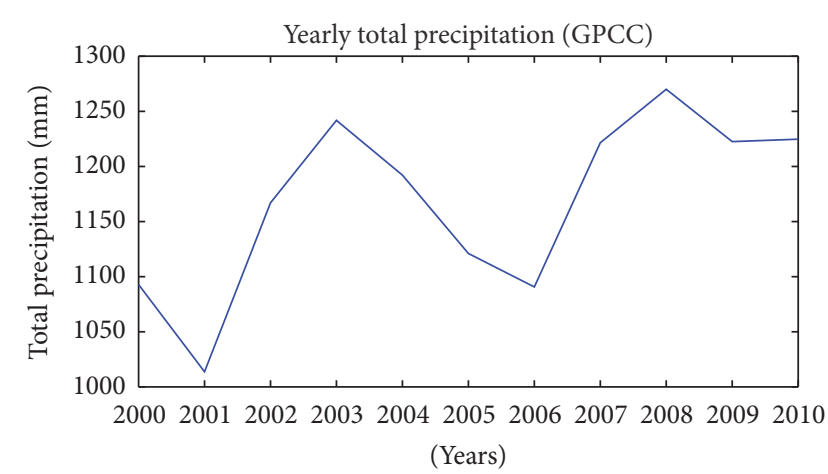

FIGURE 1: Yearly total area mean observed (GPCC) precipitation time series for 11 years for Ghana.

A nested run of two domains, coarse domain (d01) at $50 \mathrm{~km}$ horizontal resolution and inner domain (d02) (study area) at $10 \mathrm{~km}$ resolution, was used for the study, Figure 2(a). The top of the model was set to $20 \mathrm{hPa}$. This is done to make sure the tropical troposphere depth is well resolved by the model.

The integration time for the run is 9 months starting from March 1 for both years. In both experiments, Conf1 (simulation 1) to Conf7 (simulation 7), the same combination of physics parameterization schemes was used as shown in Table 2. SST and albedo were updated for all the seven configurations.

2.4. Validation Data. Evaluation of WRF configurations was done by comparing outputs from WRF configurations and two different sets of data. The gridded precipitation data from Global Precipitation Climatology Center version 7 (GPCC v7) as described in Schneider et al. [30] was used for this study. This dataset covers the period from 1901 to 2013 and on monthly temporal resolution using over 51,000 gauge station datasets across the globe gridded at 0.5-degree spatial resolution with grid density between 0 and 64 stations. Gridded precipitation data remains a good substitute for gauge observation data especially in areas where reliable and dense observational data is not available, for example, Paeth et al. [31]; Nicholson et al. [32]; and Koutsouris et al. [33]. Over Ghana, due to the coarse nature of gauge stations, the GPCC data have an average of 1 station per grid. WRF configuration simulations results are also compared with precipitation output of the ERA-Interim reanalysis data. It is worth noting that 


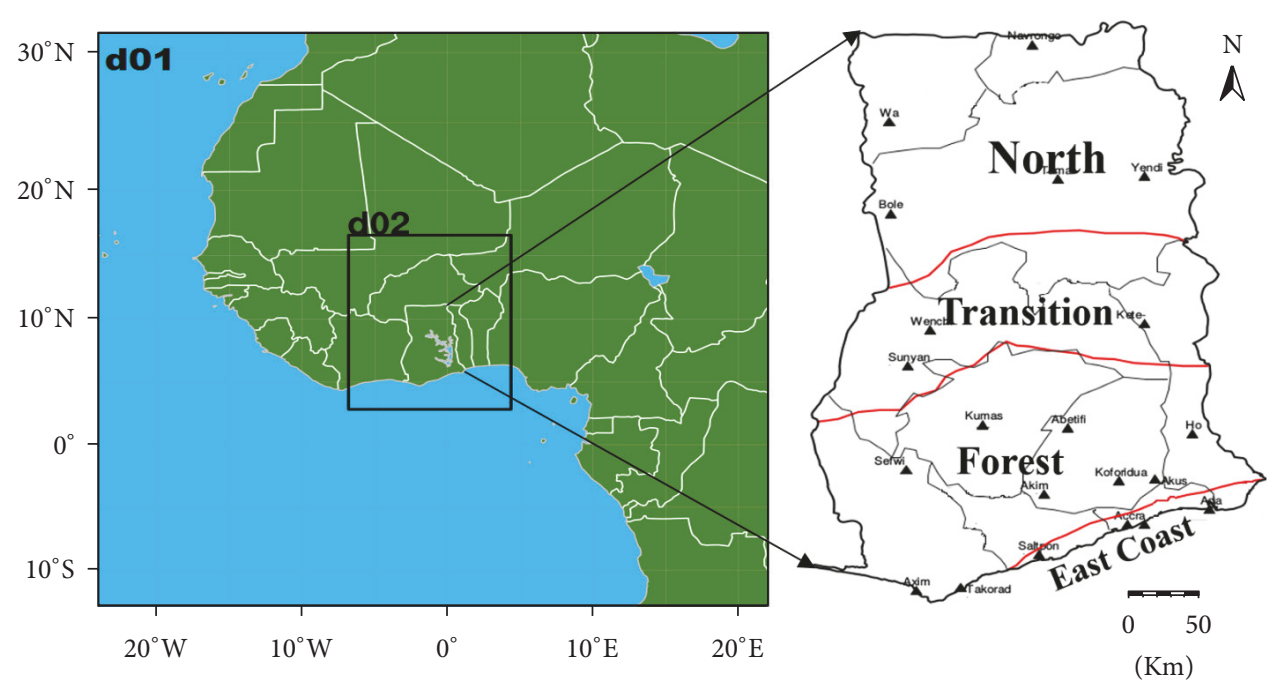

(a) Nested domain

(b) Ghana with the four agroecological zones

Figure 2: (a) Nested domain, inner domain (d02), at $10 \mathrm{~km}$ resolution and the outer domain (d01) at $50 \mathrm{~km}$ resolution with (b) the study area, Ghana, projected out with the four agroecological zones (adopted from Ghana Meteorological Agency).

the meteorological parameters from ERA-Interim reanalysis data used in forcing the WRF model simulations did not include precipitation. The GPCC data and the ERA-Interim data were remapped with the WRF for the validation.

2.5. Data Processing. The following statistics, the correlation $(R)$ (the temporal pattern between the simulated and the observed), the root mean square error (RMSE), and the standardized deviations $(\sigma)$ (the temporal variability between the simulated and observed) were calculated from the total monthly precipitation over the eight-month period out of the nine-month integration time with the first month used as spin-up. The relative biases (RB) from the total precipitation of the whole period of the simulation ( 8 months) for each configuration were also constructed. The following equations were used:

$$
\begin{aligned}
\mathrm{RB} & =\frac{\text { Model }- \text { Observed }}{\text { Observed }} \times 100 \%, \\
R & =\frac{(1 / N) \sum_{n=1}^{N}\left(f_{n}-\bar{f}\right)\left(r_{n}-\bar{r}\right)}{\sigma_{f} \sigma_{r}}, \\
\mathrm{RMSE} & =\sqrt{\frac{1}{N} \sum_{n=1}^{N}\left[\left(f_{n}-\bar{f}\right)\left(r_{n}-\bar{r}\right)\right]^{2}}, \\
\sigma_{f} & =\sqrt{\frac{1}{N} \sum_{n=1}^{N}\left(f_{n}-\bar{f}\right)^{2}}, \\
\sigma_{r} & =\sqrt{\frac{1}{N} \sum_{n=1}^{N}\left(r_{n}-\bar{r}\right)^{2},}
\end{aligned}
$$

where (1), (2), (3), (4a), and (4b) are the relative bias, correlation, RMSE, standard deviation of the simulated field, and the standard deviation of the observed, respectively. Also, $r$ is the observed field and $f$ is the simulated field.

\section{Results}

3.1. Evaluation of WRF Performance. The performance of each configuration used in the WRF model with the ERAInterim reanalysis as forcing data over the whole of Ghana and the four agroecological zones (i.e., coastal zone (east coastal zone), forest belt, transitional zone, and northern zone), Figure 2(b), by comparing estimated precipitation from the ERA-Interim and the WRF configurations (Conf) with the GPCC data (observation) in terms of relative biases, correlation, RMSE, and standard deviation is discussed. The WRF ensemble mean (WRF-EM) of the best performing Confs for each zone was also generated. This is done by averaging the various statistics ( $R, \sigma$, and RMSE) for the selected best performing members (Confs). Note that, to achieve the best results, different Confs are sometimes chosen for different zones and for different years to achieve the best possible statistics ( $R, \sigma$, and RMSE). This is because the various Confs are performed differently from one zone to another and differently for the dry and the wet years.

\subsection{Spatial Distribution of Relative Bias in Rainfall over Ghana for the Dry Year (2001) and the Wet Year (2008)}

The Dry Year (2001). Except for Conf1 (the combination of WSM6, BMJ, and YSU schemes) and Conf7 (WSM5, BMJ, and YSU), all the WRF configurations overestimated precipitation along the coast which is consistent with earlier works over this region, for example, Klutse et al. [34]. This wet bias could be attributed to the overexaggeration of the effect of the sea on this areas. Almost all the configurations did well in simulating the observed precipitation over the 


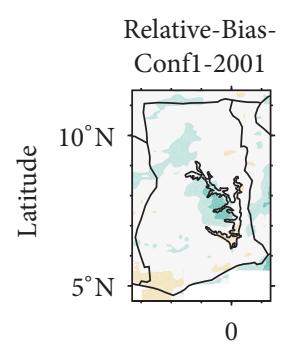

Longitude

Relative-Bias-

Conf4-2001

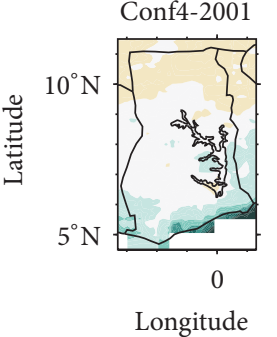

Longitude

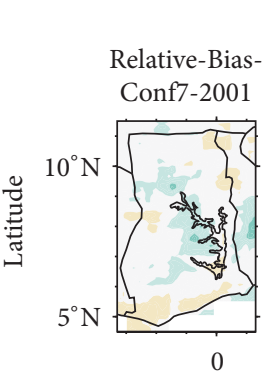

Longitude

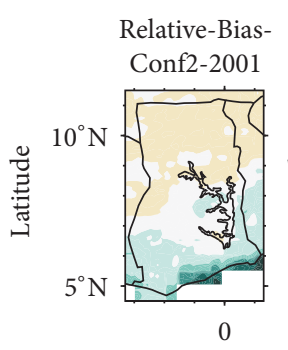

Longitude

Relative-Bias-

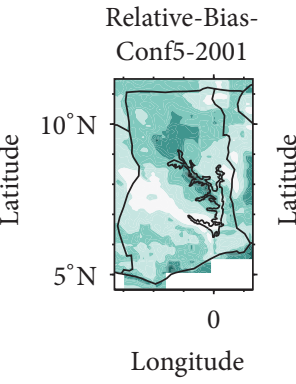

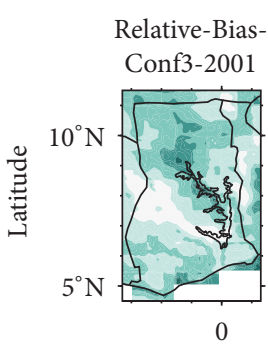

Longitude

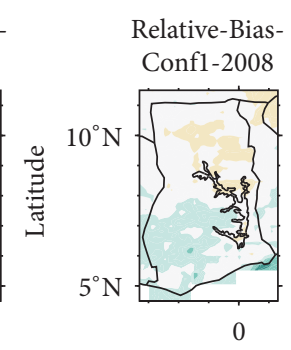

Longitude

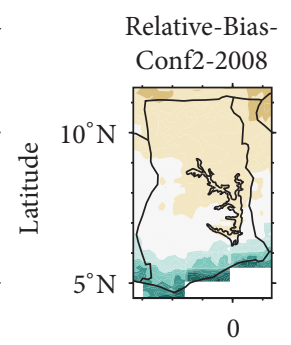

Longitude

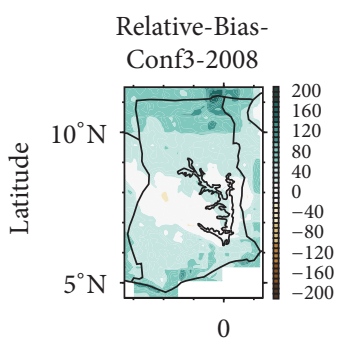

Longitude

Relative-BiasConf6-2001
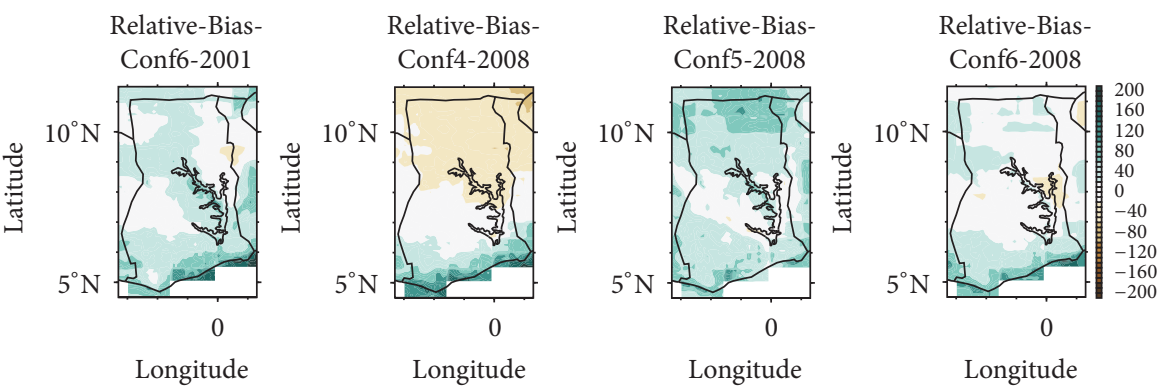

Relative-Bias (ERAInterim and GPCC) 2001

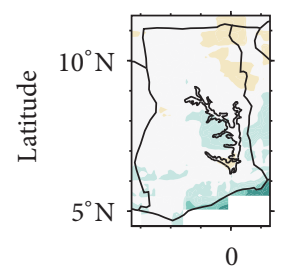

Longitude

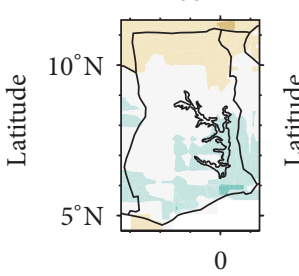

Longitude

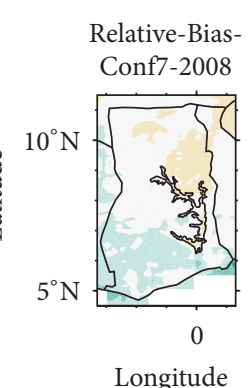

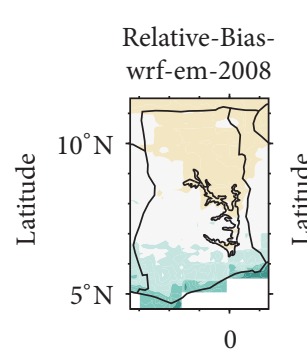

Longitude
Relative-Bias (ERAInterim and GPCC) 2008

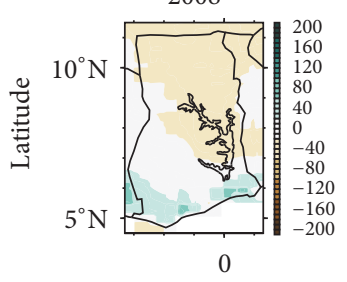

Longitude

FIGURE 3: Relative bias (\%) between all the configurations, ERA-Interim, and GPCC for the dry year (2001) and the wet year (2008) simulations.

western parts of the transitional and forest zones (Figure 3). The northern parts were generally underestimated by Conf 2 (WSM6, BMJ, and ACM2) and Conf4 (WSM5, BMJ, and ACM2) which agrees with earlier studies over West Africa performed in either Numerical Weather Prediction or climate modes, for example, Klutse et al. [34], Vizy and Cook [35], and Annor et al. [25]. The dry bias in the forcing data is seen to be translated into the WRF simulations from Conf2 (WSM6, BMJ, and ACM2) and Conf4 (WSM5, BMJ, and ACM2) for both the dry and the wet years. Also, precipitation over the western coast was underestimated by Conf1 (WSM6, BMJ, and YSU) and Conf7 (WSM5, BMJ, and YSU) showing that the effect of the microphysics schemes WSM6 and WSM5 in these two configurations performed very similar over this area. It is also seen from Figure 3 that replacing YSU with ACM2 in Conf1 (WSM6, BMJ, and YSU) and Conf7 (WSM5, BMJ, and YSU) as in Conf2 (WSM6, BMJ, and ACM2) and Conf4 (WSM5, BMJ, and ACM2) produces reverse bias over the coastal and the northern zones. Generally, all the configurations overestimated precipitation over the Volta Lake and its environs consistent with the study of Annor et al. [25] over the Volta basin. This could be due to the lake temperatures not being updated appropriately in the model.
Conf7 (WSM5, BMJ, and YSU) recorded the least mean bias of 2.9\%, while Conf5 (WSM6, GD, and YSU) recorded the highest of $63.8 \%$. All the configurations used in this study overestimated precipitation in general. The WRF-EM (Conf1, Conf3, Conf6, and Conf7) showed a great skill in simulating precipitation over the coast especially to the west, the forest zone, the transitional zone, and over the north. The Volta Lake area was also fairly well simulated. The ERA-Interim with spatial bias of about $0.7 \%$ seems to give a better estimate on average across the country.

The Wet Year (2008). Generally, Conf1 (WSM6, BMJ, and YSU) and Conf7 (WSM5, BMJ, and YSU) performed better (Figure 3) in estimating precipitation amount compared to the driving data especially over the middle and northern parts of the country. However, Conf2 (WSM6, BMJ, and ACM2), Conf4 (WSM5, BMJ, and ACM2), and Conf6 (WSM6, GD, and ACM2) simulated well over the forest zone of Ghana with bias close to zero. Overestimation over the north is well pronounced from Conf3 (WSM5, GD, and YSU) and Conf5 (WSM6, GD, and YSU) which is similar to their performance for the dry year (Figure 3), while Conf2 (WSM6, BMJ, and ACM2) and Conf4 (WSM5, BMJ, and ACM2) 


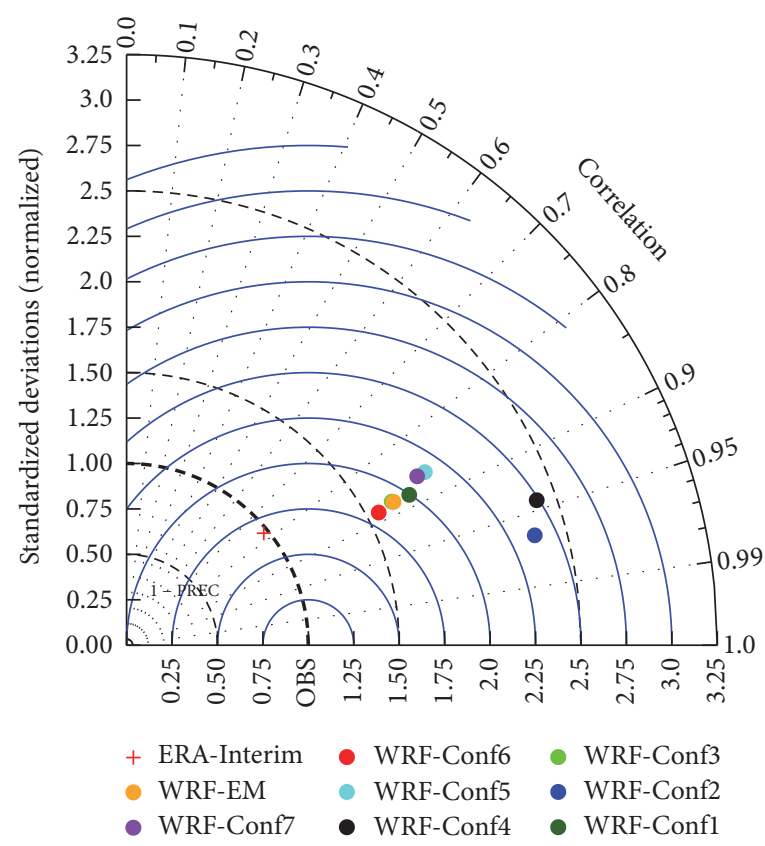

(a) Dry year (2001)

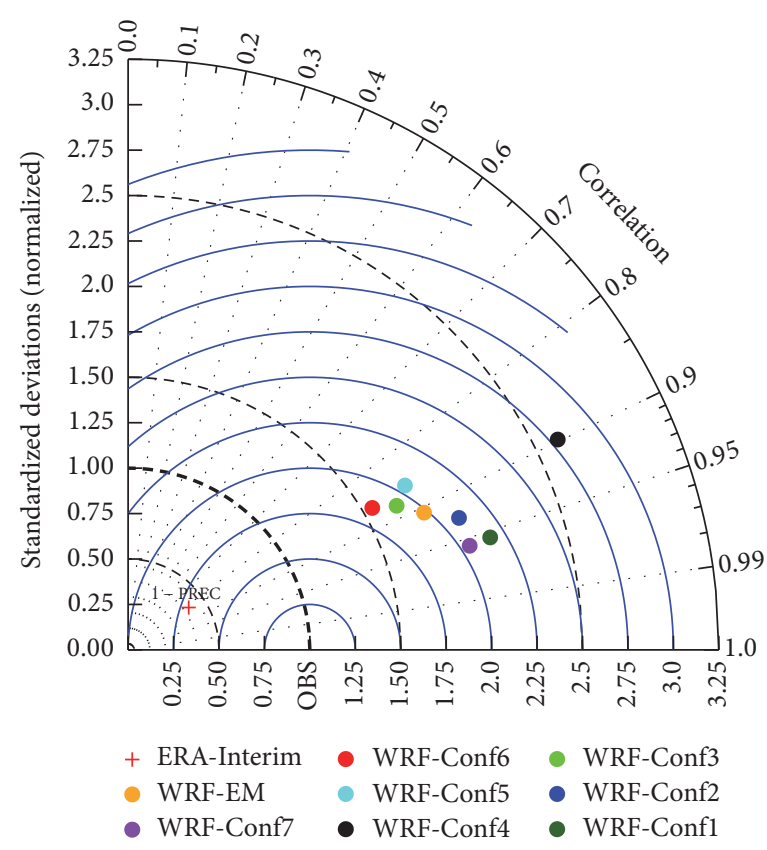

(b) Wet year (2008)

FIGURE 4: Taylor diagram showing the statistical summary for Ghana for the (a) dry year (2001) and (b) wet year (2008).

underestimated over the same zone. All the configurations, except Conf1 (WSM6, BMJ, and YSU) and Conf7 (WSM5, $\mathrm{BMJ}$, and YSU), are clearly overestimated along the coast. Conf4 (WSM5, BMJ, and ACM2) recorded the least mean bias of 3.0\%. The WRF-EM (Conf1, Conf3, Conf6, and Conf7) on average simulated almost zero mean bias across the country, underestimating the observed precipitation by $0.1 \%$. Underestimating marginally over the north, the WRF-EM clearly simulated the observed data over the middle portion of the country while overestimating over the extreme south of Ghana. It is seen from Figure 3 that configurations 1, 3, 6 , and 7 generally overestimated the observed data, while configurations 2 and 4 underestimated it.

The underestimation (overestimation) by the schemes over the northern (coastal) zone can be attributed to overexaggeration of the effect of the dry Sahel (Ocean) on the northern (coastal) zone of Ghana.

3.3. Model Performance over Ghana and the Agroecological Zones on Monthly Scale. Statistical comparisons of WRF simulations from the seven configurations forced by the ERA-Interim were evaluated for a dry year (2001) and a wet year (2008) from April through November. The results are summarized on the Taylor diagrams (e.g., Figure 4). The statistical parameters used include the correlation $(R)$, root mean square error (RMSE), and the standard deviation $(\sigma)$ for the whole country and the different agroecological zones. The WRF ensemble mean (WRF-EM) for the best performing configurations (simulations) for each zone is also represented. Note that Confs or simulations recording $\sigma>$ 3.25 are out of the scale used and therefore are not represented on the Taylor diagrams.
3.3.1. Simulation for Ghana. Considering the simulations for the entire country as a unit (Figure 4) for the dry year (2001), Conf2 (WSM6, BMJ, and ACM2) recorded the highest correlation of 0.97 but overestimated the reference temporal variability by $133 \%$. Conf6 (WSM6, GD, and ACM2) recorded the least RMSE of 0.83 and overestimated the observed temporal variability by $57 \%$ being the best in simulating the temporal variability of the observed precipitation. Conf4 (WSM5, BMJ, and ACM2) recorded the highest RMSE of 1.50 and the least correlation of 0.86 was recorded by Conf5 (WSM6, GD, and YSU) and Conf7 (WSM5, BMJ, and YSU) (Table 3).

For the wet year (Figure 4), like the dry year, all the configurations overestimated the temporal pattern of the observed precipitation and recorded correlations of 0.85 and above. Conf7 (WSM5, BMJ, and YSU) recorded the highest correlation of 0.96, while Conf5 (WSM6, GD, and YSU) recorded the least value of 0.85 . Conf4 (WSM5, BMJ, and ACM2) recorded the highest RMSE of 1.80, while Conf6 (WSM6, GD, and ACM2) recorded the lowest of 0.85 and overestimated the temporal variability of the observed precipitation by $55 \%$. The WRF-EM (Conf1, Conf3, and Conf6) correlated with $R=0.88$, while the ERA-Interim recorded 0.77 for the dry year. For the wet year, WRF-EM (Conf2, Conf3, Conf6, and Conf7) and ERA-Interim recorded correlation of 0.91 and 0.82 , respectively, with RMSE of 0.95 and 0.70 . Changing the cumulus scheme from BMJ to GD in Conf3 (WSM5, GD, and YSU), Conf5 (WSM6, GD, and YSU), and Conf6 (WSM6, GD, and ACM2) greatly improved the scores in terms of RMSE and standard deviation as seen in Table 3.

In general, Conf6 (WSM6, GD, and ACM2) (Conf4 (WSM5, BMJ, and ACM2)) performed the best (worst) for both years over Ghana. Furthermore, Conf6 (WSM6, 
TABLE 3: The four different statistics, for the whole of Ghana as a unit, for the (a) dry year and (b) wet year.

(a) Dry year (2001)

\begin{tabular}{lcccc}
\hline Confs & $R$ & $\Sigma$ & RMSE & BIAS \\
\hline Conf1 & 0.88 & 1.76 & 1.00 & 1.38 \\
Conf2 & 0.97 & 2.33 & 0.88 & 3.00 \\
Conf3 & 0.88 & 1.66 & 1.50 & 61.99 \\
Conf4 & 0.94 & 2.39 & 1.13 & 4.13 \\
Conf5 & 0.86 & 1.90 & 0.82 & 33.77 \\
Conf6 & 1.57 & 1.11 & 2.93 \\
Conf7 & 0.88 & 1.85 & 0.88 & 4.06 \\
WRF-EM & 0.86 & 1.89 & 0.65 & 0.70 \\
ERA & 0.88 & 0.97 & &
\end{tabular}

(b) Wet year (2008)

\begin{tabular}{lcccc}
\hline Confs & $R$ & $\sigma$ & RMSE & BIAS \\
\hline Conf1 & 0.95 & 2.09 & 1.15 & 5.39 \\
Conf2 & 0.93 & 1.96 & 1.10 & -7.43 \\
Conf3 & 0.88 & 1.70 & 0.90 & 48.79 \\
Conf4 & 0.90 & 2.63 & 1.80 & -2.98 \\
Conf5 & 0.85 & 1.77 & 1.06 & 43.84 \\
Conf6 & 1.55 & 0.85 & 21.09 \\
Conf7 & 0.86 & 1.96 & 1.06 & 4.68 \\
WRF-EM & 0.96 & 1.79 & 0.95 & -0.09 \\
ERA & 0.91 & 0.41 & 0.70 & -13.35 \\
\hline
\end{tabular}

GD, and ACM2) is more representative and reproduced the observed data and added value to the ERA-Interim (forcing data) for the wet year. For the dry year, however, the driving data (the ERA-Interim) seem to almost reproduce the temporal variability of the observed data over the country though with a relatively poorer correlation compared with simulation from all the WRF configurations.

3.3.2. Simulation for Coastal Zone. Mostly for biases related to WRF-EM, the only case where the WRF-EM may do better than the individual members is where there is a mix of overestimation and underestimation over the same zone. Due to this, the WRF-EM does not improve on individual simulations over the agroecological zones because the model either overestimated/underestimated over the coastal/northern zones and therefore the WRF-EM is only meaningful considering the entire country as a unit. Therefore, the biases for WRF-EM are not recorded for the agroecological zones. Also, RMSE values for Confs recording $\sigma>3.25$ (which are not represented on the Taylor diagrams) are also ignored.

The results for dry year (Figure 5) show that Conf3 (WSM5, GD, and YSU) produced the highest correlation $(R$ $=0.84$ ), while Conf4 (WSM5, BMJ, and ACM2) recorded the lowest of 0.45 (not represented on the diagram). All the configurations overestimated the observed variability. The results in this study are consistent with earlier studies performed using the WRF model over Africa by Klutse et al. [34]. The combination of WSM6, BMJ, and YSU schemes in Confl, however, agreed best with observation having the least RMSE and temporal variability of around 1 (the same as the observation), while Conf2 (WSM6, BMJ, and ACM2) recorded the highest temporal variability of 5.26 (which is outside the scale used in this study and therefore not showing on the diagram). The effect of the ACM2 in combination with WSM6 and BMJ in this zone may not be good in improving the skill of the model in simulating precipitation over Ghana. All the configurations added value to the driving data in terms of correlation but only Conf1 (WSM6, BMJ, and YSU) and Conf7 (WSM5, BMJ, and YSU) produced better temporal variability and better RMSE. The WRF-EM (Conf1, Conf6, and Conf7) recorded correlation of 0.81 and RMSE of 0.95 (Table 4) and overestimated the temporal variability by $148 \%$. Conf7 (WSM5, BMJ, and YSU) produced the least bias (bias close to $0 \%$ ) in total precipitation over this zone. The ERA-Interim reanalysis data recorded correlation of 0.63 and RMSE of 1.10 and overestimated the observed temporal variability by $38 \%$. Conf1 (WSM6, BMJ, and YSU) and Conf7 (WSM5, BMJ, and YSU) performed very similarly giving an indication that the effect of the MPS scheme in these two configurations may be very similar in this zone.

For the wet year (2008), Conf5 (WSM6, GD, and YSU) and Conf3 (WSM5, GD, and YSU) recorded best correlations all above 0.8. All the configurations including WRF-EM (Conf3, Conf5, and Conf7) recorded RMSE above 2.0. None of the configurations added value to the driving data in terms of RMSE unlike in the dry year. ERA-Interim recorded the best root mean square error of 0.85 and overestimated the temporal variability by $54 \%$ but with the worst correlation of 0.54 . 


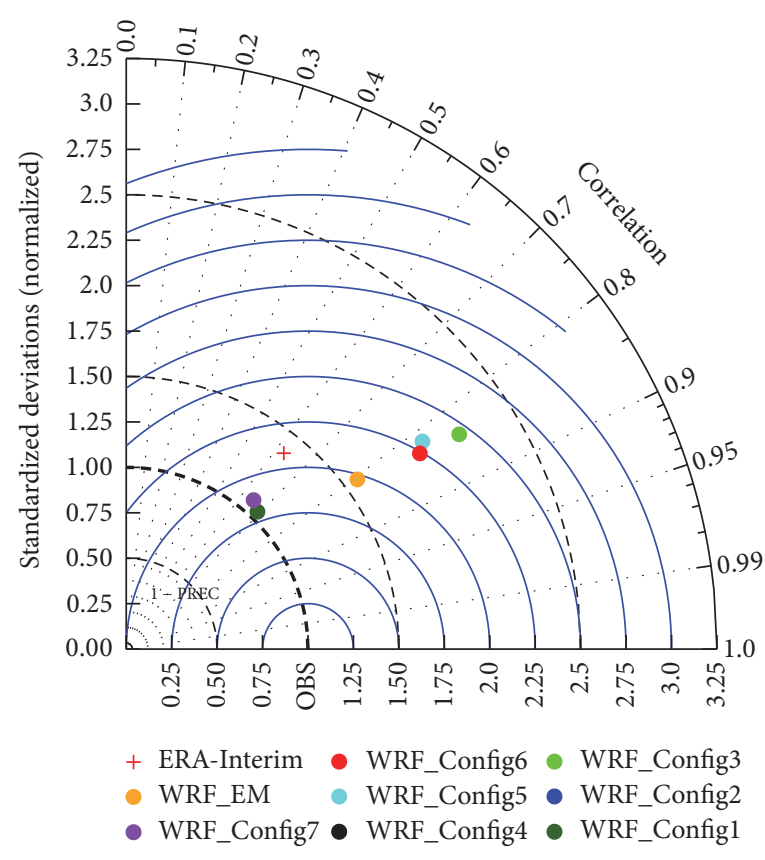

(a) Dry year (2001)

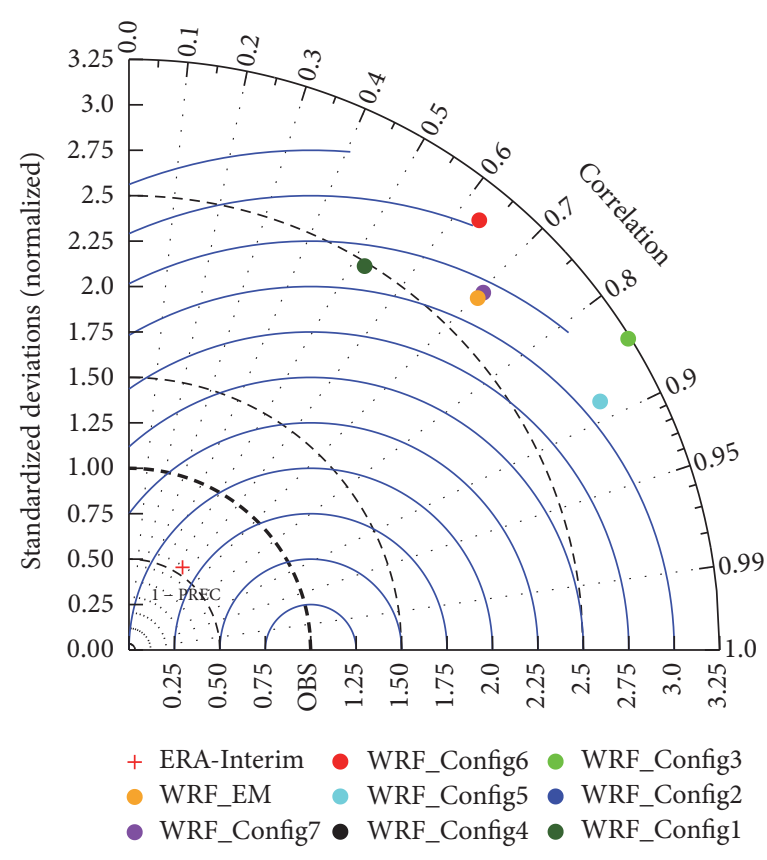

(b) Wet year (2008)

Figure 5: Taylor diagram showing the statistical summary for the coastal zone for the (a) dry year (2001) and (b) wet year (2008).

TABLE 4: The four different statistics, for the coastal zone, for the (a) dry year (2001) and (b) wet year (2008).

(a) Dry year (2001)

\begin{tabular}{lcccc}
\hline Confs & $R$ & $\sigma$ & RMSE & BIAS \\
\hline Conf1 & 0.69 & 1.05 & 0.81 & - \\
Conf2 & 0.47 & 5.26 & 1.44 & 84.00 \\
Conf3 & 0.84 & 2.18 & - & 77.90 \\
Conf4 & 0.45 & 4.48 & 1.31 & 73.40 \\
Conf5 & 0.82 & 1.99 & 1.20 & 36.70 \\
Conf6 & 0.83 & 1.94 & 0.88 & 32.20 \\
Conf7 & 0.65 & 1.08 & 0.95 & 0.05 \\
WRF-EM & 0.81 & 1.61 & 1.10 & 35.50 \\
ERA & 0.63 & 1.38 & & \\
\hline
\end{tabular}

(b) Wet year (2008)

\begin{tabular}{lcccc}
\hline Confs & $R$ & $\sigma$ & RMSE & BIAS \\
\hline Conf1 & 0.52 & 2.48 & 2.15 & 32.40 \\
Conf2 & 0.07 & 4.96 & 2.75 & 77.60 \\
Conf3 & 0.85 & 3.24 & - & 217.10 \\
Conf4 & 0.26 & 7.69 & 2.10 & 83.50 \\
Conf5 & 0.88 & 2.93 & 2.80 & 59.30 \\
Conf6 & 0.63 & 3.05 & 2.15 & 75.00 \\
Conf7 & 0.70 & 2.77 & 2.13 & 40.70 \\
WRF-EM & 0.81 & 2.98 & 0.85 & - \\
ERA & 0.54 & 0.54 & & 24.30 \\
\hline
\end{tabular}




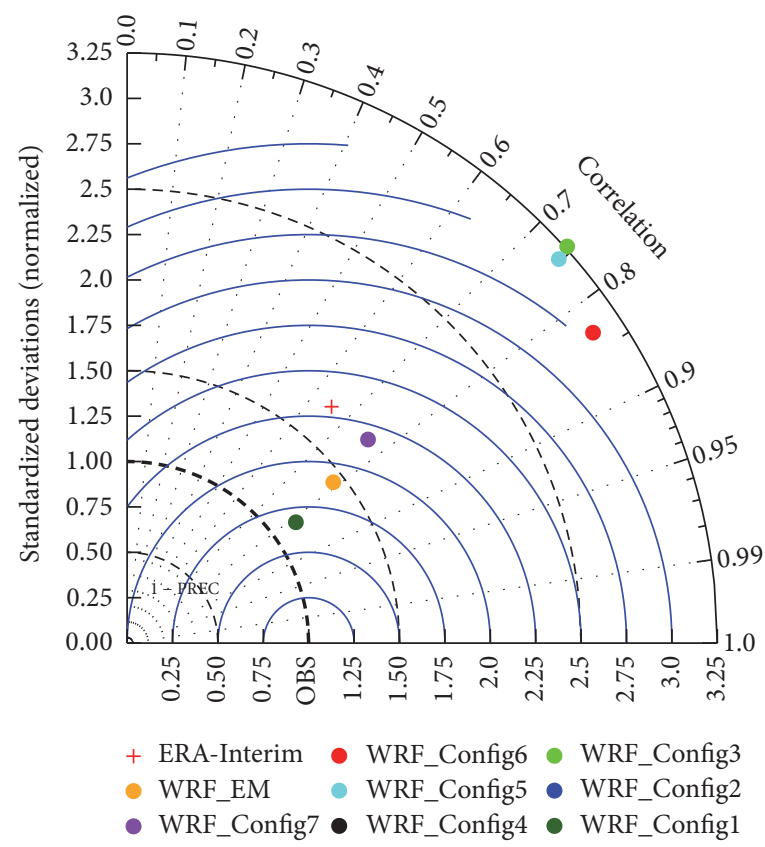

(a) Dry year (2001)

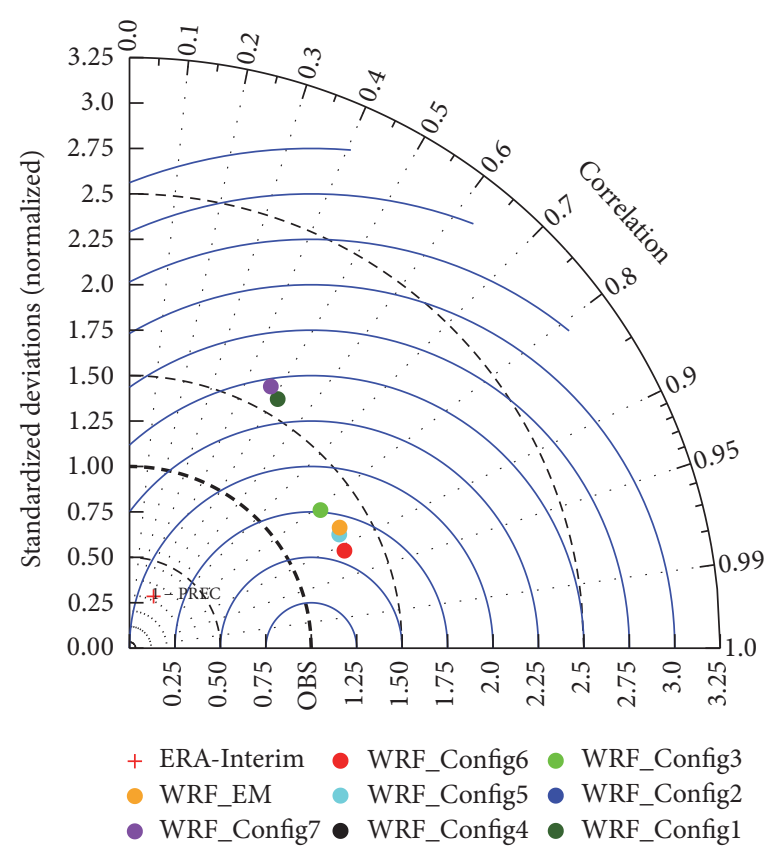

(b) Wet year (2008)

FiguRE 6: Taylor diagram showing the statistical summary for the forest zone for the (a) dry year (2001) and (b) wet year (2008).

3.3.3. Simulation for Forest Zone. From (Figure 6), Conf6 (WSM6, GD, and ACM2) correlated the best with the observation recording 0.83 and 0.91 in 2001 and 2008, respectively (Table 5). Conf2 (WSM6, BMJ, and ACM2) recorded the lowest correlation in both years $(R=0.73$ for 2001 and $R$ $=0.13$ for 2008). The simulation in this zone sees all the WRF configurations and the WRF-EM (Conf1 and Conf7) overestimating the observed variability for both wet and the dry years which is consistent with the earlier study performed by Annor et al. [25] where the WRF model generally overestimated observation. Conf1 (WSM6, BMJ, and YSU) produced estimates with the least variability of positive $14 \%$ for the dry year and the worst are Conf4 (WSM5, BMJ, and ACM2) and Conf2 (WSM6, BMJ, and ACM2) recording the largest, overestimating the observed variability by $436 \%$ and $462 \%$ respectively, for the dry year and $480 \%$ and $301 \%$, respectively, for the wet year. This shows that the combination of BMJ and ACM2 in these two scheme configurations are not able to reproduce the observed precipitation and, therefore, not suitable for use over the forest zone. Conf1 (WSM6, BMJ, and YSU) and Conf7 (WSM5, BMJ, and YSU) both produced a bias below $7 \%$ above the observed total seasonal precipitation over this zone for the dry year. WRF-EM (Conf3, Conf5, and Conf6) overestimated the observed variability with the same magnitude as that of Conf6 (WSM6, GD, and ACM2) for the dry year but with relatively lower correlation and higher RMSE.

3.3.4. Simulation for Transitional Zone. For the transitional zone, Conf6 (WSM6, GD, and ACM2) performed the best with the lowest RMSE and one of the best standard deviations for both wet and dry years. Conf5 (WSM6, GD, and YSU) and Conf7 (WSM5, BMJ, and YSU) recorded the highest correlation of 0.80 and 0.91 , respectively (Table 6), for the dry and wet years (Figure 7). All the configurations overestimated the observed variability for both years. Conf2 (WSM6, BMJ, and ACM2) recording the least $\sigma$ of 1.35 and the highest RMSE of 1.65 was recorded by Conf7 (WSM5, BMJ, and YSU). The forcing data underestimated the observed temporal variability by $16 \%$ and $75 \%$, respectively, for the dry and wet years and recorded one of the lowest correlations $(R=0.62)$ but with better RMSE of 0.85 and. Conf6/Conf7 produced a bias below/above $2 \%$ of the observed total seasonal precipitation over this zone for the wet year.

The WRF_EM correlates with the observed data with $R=$ 0.79 (Conf3 and Conf5) and $R=0.79$ (Conf2 and Conf6) for the dry and wet years, respectively, which is an improvement upon the simulation from the driving data and with RMSE of 1.06 and 0.95 , respectively, for the dry and the wet years. The results show that, unlike the dry year, the WRF configurations and the WRF-EM performed mostly better than the forcing data.

3.3.5. Simulation for Northern Zone. All the WRF configurations in this zone performed well in terms of correlation for both years (Figure 8), with Conf3 (WSM5, GD, and YSU) recording the highest correlation for both years. Conf1 (WSM6, BMJ, and YSU), Conf3 (WSM5, GD, and YSU), Conf5 (WSM6, GD, and YSU), Conf6 (WSM6, GD, and ACM2), and Conf7 (WSM5, BMJ, and YSU) overestimated the observed variability, while Conf2 (WSM6, BM), and ACM2) and Conf4 (WSM5, BMJ, and ACM2) underestimated it. Conf4 (WSM5, BMJ, and ACM2) and Conf6 (WSM6, GD, and ACM2) recorded the least root mean square 
TABLE 5: The four different statistics, for the forest zone, (a) for the dry year and (b) for the wet year.

(a) Dry year (2001)

\begin{tabular}{lcccc}
\hline Confs & $R$ & $\sigma$ & RMSE & BIAS \\
\hline Conf1 & 0.81 & 1.14 & 0.65 & 3.50 \\
Conf2 & 0.73 & 5.62 & - & 2.65 \\
Conf3 & 0.74 & 3.26 & - & 4.40 \\
Conf4 & 0.76 & 5.36 & 2.45 & 10.10 \\
Conf5 & 0.75 & 3.18 & 2.35 & 46.30 \\
Conf6 & 0.83 & 3.08 & 1.15 & 28.60 \\
Conf7 & 0.76 & 1.74 & 0.9 & 6.10 \\
WRF-EM & 0.79 & 1.44 & 1.87 & 16.40 \\
ERA & 0.65 & 1.72 & & \\
\hline
\end{tabular}

(b) Wet year (2008)

\begin{tabular}{lcccc}
\hline Confs & $R$ & $\sigma$ & RMSE & BIAS \\
\hline Conf1 & 0.51 & 1.59 & 1.37 & 28.10 \\
Conf2 & 0.13 & 4.01 & 0.70 & 11.80 \\
Conf3 & 0.81 & 1.39 & - & 142.9 \\
Conf4 & 0.14 & 5.80 & 0.62 & 17.10 \\
Conf5 & 0.88 & 1.31 & 0.57 & 31.00 \\
Conf6 & 0.91 & 1.30 & 1.44 & 19.90 \\
Conf7 & 0.48 & 1.64 & 0.65 & 23.70 \\
WRF-EM & 0.87 & 1.33 & 0,90 & - \\
ERA & 0.42 & 0.31 & 0.80 \\
\hline
\end{tabular}

TABLE 6: The four different statistic, for the transitional zone, (a) for the dry year and (b) for the wet year.

(a) Dry year (2001)

\begin{tabular}{lcccc}
\hline Confs & $R$ & $\sigma$ & RMSE & BIAS \\
\hline Conf1 & 0.52 & 1.89 & 1.63 & 13.50 \\
Conf2 & 0.59 & 1.35 & 0.87 & -0.60 \\
Conf3 & 0.78 & 1.49 & 1.30 & 43.30 \\
Conf4 & 0.60 & 1.61 & 1.15 & 7.70 \\
Conf5 & 0.80 & 1.71 & 0.87 & 49.10 \\
Conf6 & 0.79 & 1.52 & 1.65 & 25.70 \\
Conf7 & 0.76 & 1.74 & 1.06 & 1.70 \\
WRF-EM & 0.79 & 1.61 & 0.85 & 15.80 \\
ERA & 0.62 & 0.84 & & \\
\hline
\end{tabular}

(b) Wet year (2008)

\begin{tabular}{lcccc}
\hline Confs & $R$ & $\sigma$ & RMSE & BIAS \\
\hline Conf1 & 0.87 & 2.94 & 2.15 & 6.80 \\
Conf2 & 0.81 & 1.60 & 0.95 & -21.30 \\
Conf3 & 0.52 & 1.58 & 1.35 & 107.00 \\
Conf4 & 0.79 & 1.84 & 1.15 & -13.60 \\
Conf5 & 0.53 & 1.77 & 1.50 & 16.70 \\
Conf6 & 0.77 & 1.21 & 0.85 & -1.70 \\
Conf7 & 0.91 & 2.28 & 1.40 & 1.40 \\
WRF-EM & 0.79 & 1.41 & 0.95 & - \\
ERA & 0.80 & 0.25 & 0.85 & -27.80 \\
\hline
\end{tabular}




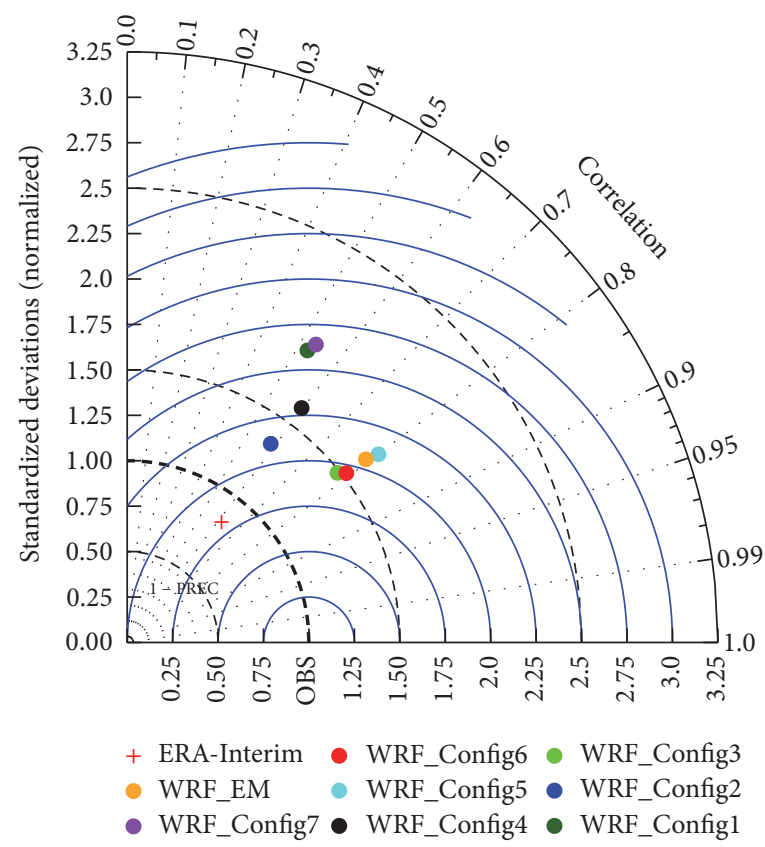

(a) Dry year (2001)

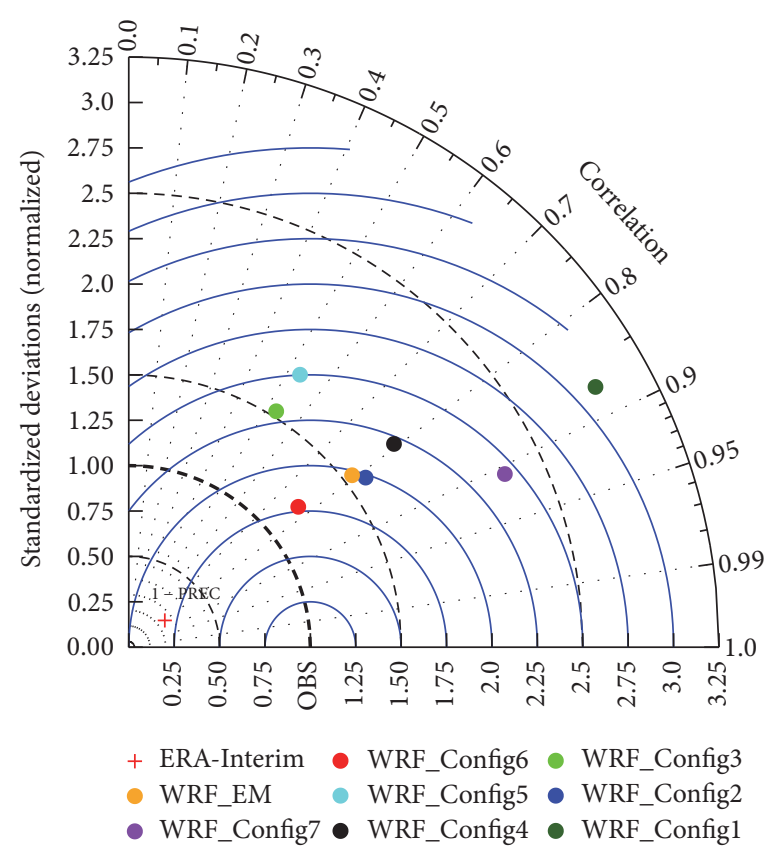

(b) Wet year (2008)

FIGURE 7: Taylor diagram showing the statistical summary for the transitional zone for the (a) dry year (2001) and (b) wet year (2008).

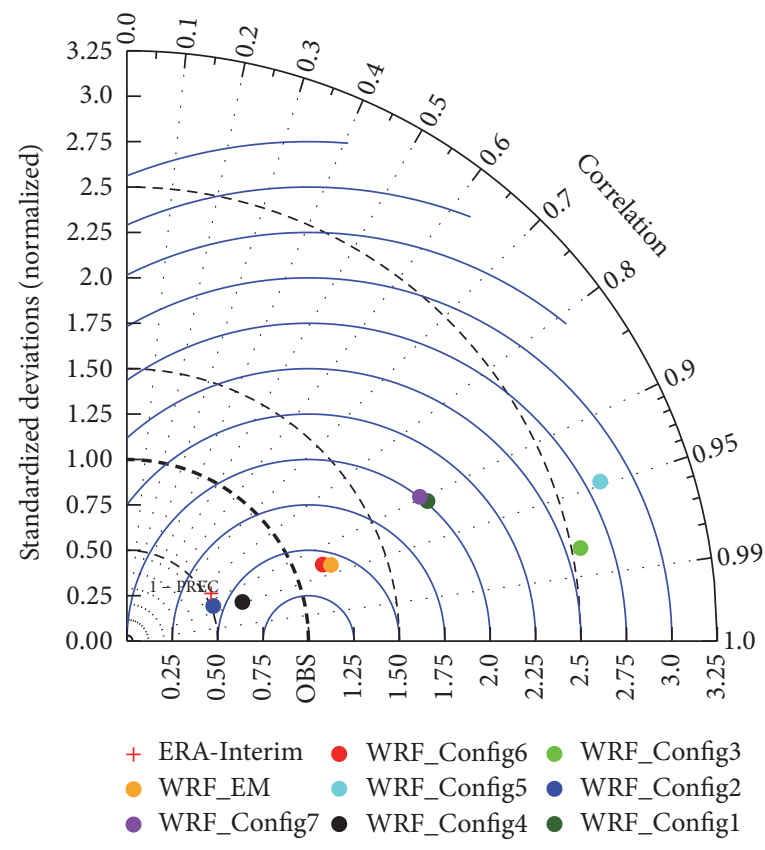

(a) Dry year (2001)

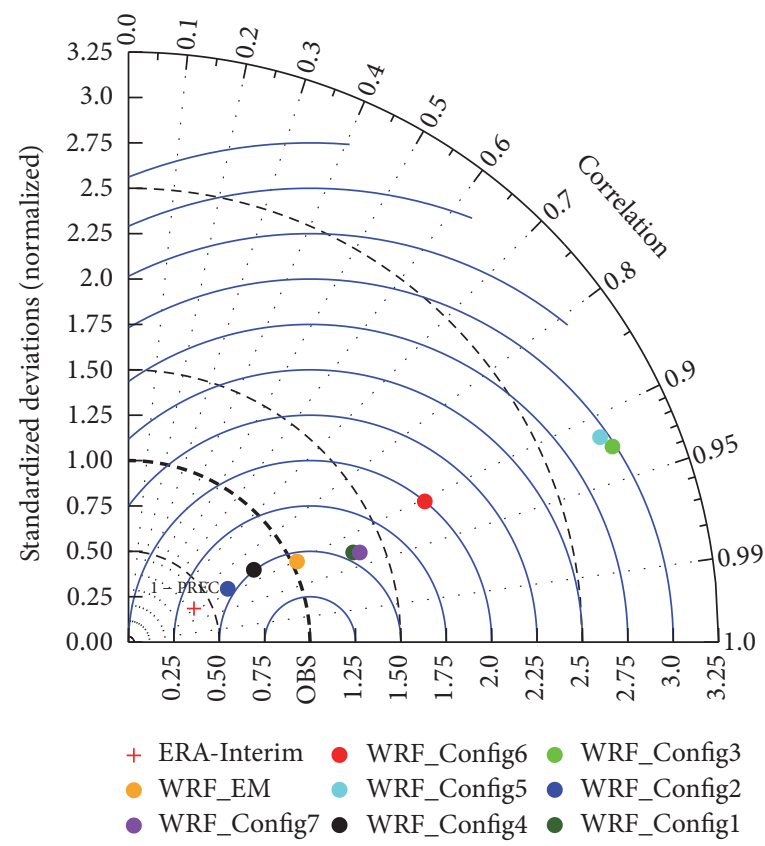

(b) Wet year (2008)

FIGURE 8: Taylor diagram showing the statistical summary for the northern zone for the (a) dry year (2001) and (b) wet year (2008).

error of 0.40 (Table 7). This shows that the effect of the PBL and YSU in Conf5 (WSM6, GD, and YSU) (recording a high RMSE and standard deviation) is counterproductive compared with ACM2 in Conf6 (WSM6, GD, and ACM2). The WRF-EM recorded correlation of 0.93 and RMSE of 0.40 and overestimated the temporal variability by $20 \%$ which is very close to the best performing Conf6 (WSM6, GD, and ACM2) which overestimated the observed variability by $16 \%$. The forcing data underestimated the observed data and recorded correlation of 0.87 and root mean square error of 0.65 and underestimated the temporal variability by $47 \%$ with performance close to that of Conf2 (WSM6, BMJ, and ACM2). Again, all the configurations improved upon the simulation of the temporal pattern of the observed data over 
TABLE 7: The four different statistic, for the northern zone, (a) for the dry year and (b) for the wet year.

(a) Dry year (2001)

\begin{tabular}{lcccc}
\hline Confs & $R$ & $\sigma$ & RMSE & BIAS \\
\hline Conf1 & 0.91 & 1.83 & 1.00 & 6.70 \\
Conf2 & 0.93 & 0.51 & 0.60 & -28.60 \\
Conf3 & 0.98 & 2.55 & 1.60 & 74.3 \\
Conf4 & 0.95 & 0.67 & 0.40 & -20.40 \\
Conf5 & 0.95 & 2.75 & 1.85 & 75.50 \\
Conf6 & 0.93 & 1.16 & 0.40 & 22.60 \\
Conf7 & 0.90 & 1.80 & 1.00 & 3.90 \\
WRF-EM & 0.95 & 1.22 & 0.40 & - \\
ERA & 0.87 & 0.53 & 0.65 & -16.50 \\
\hline
\end{tabular}

(b) Wet year (2008)

\begin{tabular}{lcccc}
\hline Confs & $R$ & $\sigma$ & RMSE & BIAS \\
\hline Conf1 & 0.93 & 1.33 & 0.55 & -11.10 \\
Conf2 & 0.88 & 0.62 & 0.55 & -39.90 \\
Conf3 & 0.93 & 2.95 & 1.95 & 157.70 \\
Conf4 & 0.87 & 0.80 & 0.50 & -37.10 \\
Conf5 & 0.92 & 2.83 & 1.94 & 52.10 \\
Conf6 & 0.90 & 1.81 & 1.00 & 12.90 \\
Conf7 & 0.93 & 1.37 & 0.56 & -12.10 \\
WRF-EM & 0.90 & 1.03 & 0.44 & - \\
ERA & 0.89 & 0.41 & 0.65 & -36.70 \\
\hline
\end{tabular}
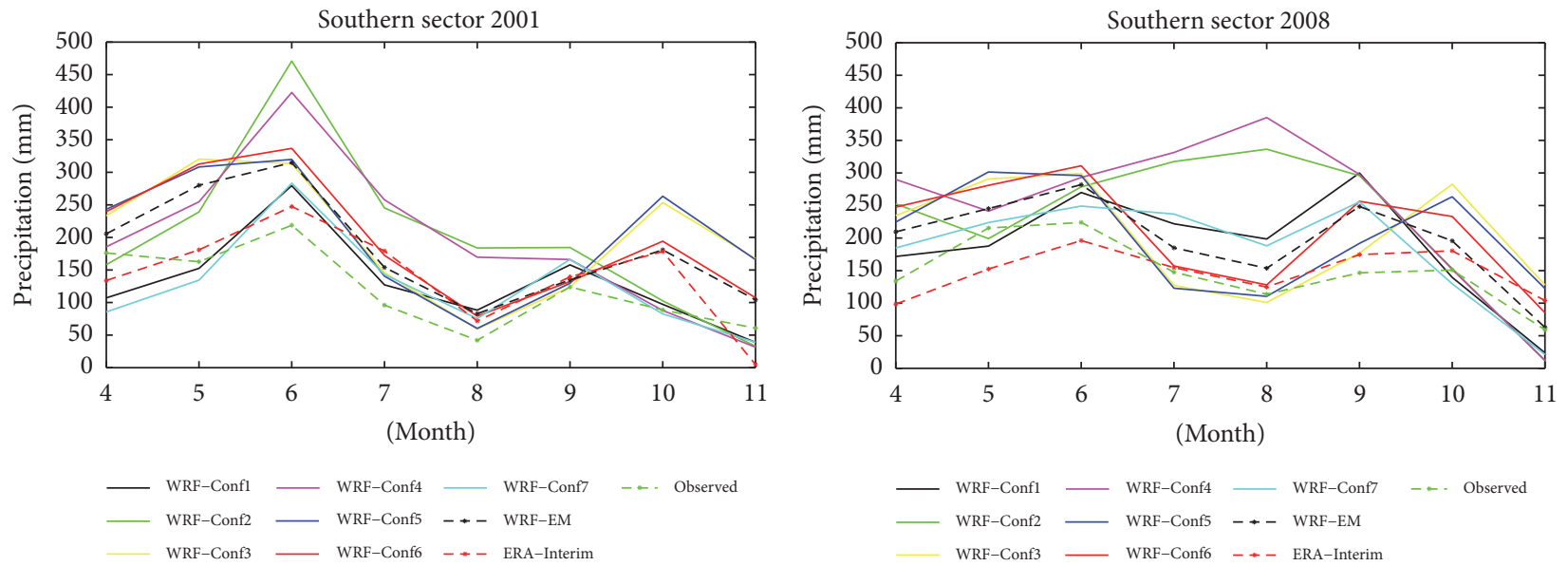

FIGURE 9: Time series plots of monthly total precipitation simulated for the southern sector of Ghana for the dry year (2001) and wet year (2008).

that from the forcing data. With the exception of Conf2 (WSM6, BMJ, and ACM2) and Conf4 (WSM5, BMJ, and ACM2), all the configurations overestimated the observed variability for the wet year with Conf7 (WSM5, BMJ, and YSU) overestimating the observed temporal variability by 37\%. Conf2 (WSM6, BMJ, and ACM2) and Conf4 (WSM5, $\mathrm{BMJ}$, and $\mathrm{ACM} 2$ ) as in the dry year underestimated the observed temporal variability by $38 \%$ and $20 \%$, respectively. The ERA-Interim recorded correlation of 0.89 and RMSE of 0.65 and underestimated the temporal variability by $49 \%$, while the WRF-EM (Conf1, Conf2, Conf4, and
Conf7) recorded correlation of 0.90 and RMSE of 0.44 and overestimated the observed temporal variability by $3 \%$. The WRF-EM almost reproduces the observed variability for both years ( $\sigma=1.22$ (Conf2, Conf3, Conf4, and Conf6) and $\sigma=1.03$ for dry and wet years, resp.).

3.4. WRF Performance over the Southern Sector for Seasonal Cycle. From the time series plots for the total monthly precipitation over southern sector (areas comprising the coastal and the forest agroecological zones) of Ghana (Figure 9), it is seen that all except Conf2 (WSM6, BMJ, and ACM2) 

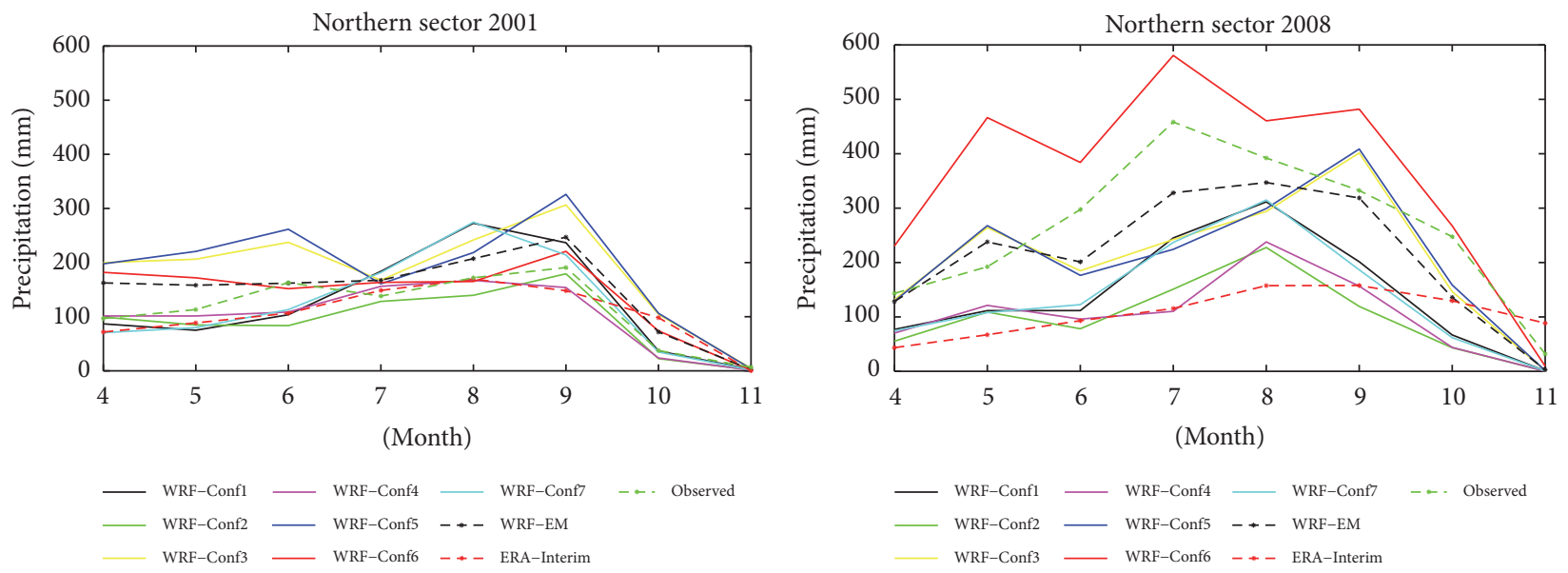

FIGURE 10: Time series plots of monthly total precipitation simulated for the northern sector of Ghana for the dry year (2001) and wet year (2008).

and Conf4 (WSM5, BMJ, and ACM2) realistically simulated the bimodal (two-peak) precipitation field observed over southern Ghana for both the dry and wet years. The seasonal cycle of monthly precipitation is clearly simulated for all the dry year simulations. As discussed earlier and consistent with earlier studies, the general overestimation by the WRF over southern Ghana is evident in Figure 9 and consistent with earlier studies, for example, Noble et al. [36]; Klutse et al. [34]; and Annor et al. [25]. The first peak, clearly seen in June, is consistent with the peak of the major rainy season over southern Ghana. A relatively dry period within summer months described by Ireland [37], a period of less rainfall activities, is also clearly depicted in August as seen in all the simulations except those performed by Conf2 (WSM6, BMJ, and ACM2) and Conf4 (WSM5, BMJ, and ACM2). The peak of the minor season (September/October) is also clearly depicted.

For the wet year (2008), configurations 1, 3, 5, 6, and 7 simulated well the seasonal cycle of precipitation observed over southern Ghana with Conf6 (WSM6, GD, and ACM2) simulating best the phase of the observed. Even though Configurations 1 and 7 are in phase with the observed data, they both are simulated far above normal rainfall in August. However, estimates from Conf2 (WSM6, BMJ, and ACM2) and Conf4 (WSM5, BMJ, and ACM2) are clearly out of phase and depicted a unimodal cycle peaking around August which is inconsistent with the observed data.

3.5. WRF Performance over the Northern Sector for Seasonal Cycle. The time series plots over northern sector (areas comprising the transitional and the northern zones) of Ghana exhibit a unimodal rainfall season from May through October which peaks in August/September (Figure 10) as simulated by configurations $1,2,4$, and 7 . All the configurations in this sector also generally overestimated the observed precipitation. However, Conf3 (WSM5, GD, and YSU) and Conf5 (WSM6, GD, and YSU) exhibit some traits of bimodal precipitation pattern (Figure 10) with the major peak occurring in August/September. The bimodal nature of rainfall is not characteristic of the northern sector but their peak in September is in phase with observation. Only Conf2 (WSM6, BM), and ACM2) and Conf6 (WSM6, GD, and ACM2) actually simulated the peak of the observed in September, with good estimates. Only Conf2 (WSM6, BM), and ACM2) and Conf6 (WSM6, GD, and ACM2) actually simulated the peak of the observed data in September, with good estimates for the dry year. For the wet year (2008), apart from Conf1 (WSM6, BMJ, and YSU), there is a fairly good simulation of total monthly precipitation especially from configurations 1, 2, 6, and 7. Conf6 (WSM6, GD, and ACM2) again is the only scheme combination able to simulate the peak of the observed in July, while most others peak in August. Configurations 3, 4, and 5, however, show a bimodal rainfall pattern but peaks at the right period of August/September. The forcing data is seen to give a good pattern close to observation for both years even though the pattern seems somehow bimodal for the wet year. The patterns in both cases (dry and wet year) are unimodal shapes consistent with observation even though peaking earlier/later than observation for the dry/wet year.

\section{Summary and Discussions}

This study considered the optimal physics scheme configuration of the WRF model that will best simulate seasonal precipitation field across the agroecological zones of Ghana. This will help provide timely and accurate seasonal forecast over Ghana. WRF performance over Ghana was evaluated looking at the spatial bias, the correlation, root mean square error, and standard deviation over Ghana and its four agroecological zones and how the different scheme configurations simulate the seasonal monthly total precipitation and seasonal cycle of the precipitation field over the northern and the southern sectors of Ghana for both dry and wet years.

Generally, most of the configurations for both the dry and wet years (2001 and 2008) overestimated the observed precipitation data along the coastal zone. Good estimates were generally simulated over the western parts of the 
transitional zone and parts of the forest zone. Conf2 (WSM6, BMJ, and ACM2), Conf4 (WSM5, BMJ, and ACM2), and Conf6 (WSM6, GD, and ACM2) simulated small or no bias over the forest zones for the wet year. This could be attributed to the ACM2 PBL performing well over these zones as against those simulations from YSU (especially Conf3 and Conf5).

Conf2 (WSM6, BMJ, and ACM2), Conf4 (WSM5, BMJ, and ACM2), WRF-EM, and the forcing data underestimated generally over the northern zone for both the wet and the dry years given an indication that even though these configurations performed well over the forest zone, they might have exaggerated the effect of the dryness of the Sahel region over the northern zone. The combination of BMJ and YSU in Conf1 (WSM6, BMJ, and YSU) and Conf7 (WSM5, BMJ, and YSU) added value to the ERA-Interim estimates across the country for both years especially over the transitional belt and the forest zone, while GD in combination with YSU (as in Conf3 (WSM5, GD, and YSU) and Conf5 (WSM6, GD, and YSU)) seem generally not good in simulating precipitation amount for the study area. Conf6 (WSM6, GD, and ACM2) performed so well in 2008 (wet year) with good estimates across the country except for the coastal zone where the general overestimation occurred. However, across the entire country for both dry and wet years, Conf7 (WSM5, BMJ, and YSU) performed the best in simulating the seasonal total rainfall over Ghana.

The performance of the WRF model in terms of correlation, RMSE, and standard deviation of the spatial distribution of monthly mean rainfall over all of Ghana as a unit and the northern zone for wet and dry years performed similarly. The combination of GD and ACM2 showed great skill over these areas recording in many cases correlation above 0.8 and standard deviation close to that of the observed. This may be attributed to the variable nature of rainfall over the northern zone which is similar to considering larger areas like the whole of Ghana as a unit since different agroecological zones have their unique rainfall pattern. In a similar manner, the combination involving BMJ and YSU performed the best over the extreme southern zone of the country especially along the coast. Conf6 (WSM6, GD, and ACM2) in general produced the best scores in terms of RMSE and standard deviation for Ghana as a unit and all the agroecological zones, especially over the forest, transitional, and the northern zones which are the food basket zones and the main catchment areas of the Volta Lake. Also, simulated precipitation from scheme configurations with GD cumulus scheme as in Conf3 (WSM5, GD, and YSU), Conf5 (WSM6, GD, and YSU), and Conf6 (WSM6, GD, and ACM2) correlate better with the observed data across the country. The performance of GD over Ghana is consistent with an earlier study over West Africa (e.g., Noble et al. [36]) where combination of GD in schemes gave the best scores.

The performance of the WRF model (run at $10 \mathrm{~km}$ resolution) was better over these limited areas (agroecological zones) compared to that from the whole country as a unit. The WRF-EMs in most cases improved the skill of estimates over the forcing data which generally performed well over the entire country compared with the agroecological zones. This could be attributed to the spatial resolution of the GPCC data $(\approx 55 \mathrm{~km})$ which is more similar to that of the synoptic stations across the country which are possibly used in generating the GPCC data used in this study for validation. In summary, this result shows that WRF will be suitable in downscaling Global Circulation Models (GCMs) over Ghana and this is a good sign for the West African subregion.

\section{Conflicts of Interest}

The authors declare that there are no conflicts of interest regarding the publication of this paper.

\section{Acknowledgments}

The authors are thankful to the Ghana Meteorological Agency (GMet) for providing computing facilities for this work. The authors appreciate the contributions of the European Center for Medium-Range Weather Forecast (ECMWF) and Climate Data Guide of the National Center for Atmospheric Research websites where a link to the various datasets used in this study is provided.

\section{References}

[1] G. Masters, P. Baker, and J. Flood, "Climate change and agricultural commodities," CABI Working Paper, vol. 2, 2010.

[2] A. Tall, S. J. Mason, M. Van Aalst et al., "Using seasonal climate forecasts to guide disaster management: The Red Cross experience during the 2008 West Africa floods," International Journal of Geophysics, vol. 2012, Article ID 986016, 12 pages, 2012.

[3] A. Troccoli, M. Harrison, D. L. Anderson, and S. J. Mason, Seasonal Climate: Forecasting and Managing Risk, vol. 82, Springer Academic Publishers, London, UK, 2008.

[4] J. B. Omotosho, A. A. Balogun, and K. Ogunjobi, "Predicting monthly and seasonal rainfall, onset and cessation of the rainy season in West Africa using only surface data," International Journal of Climatology, vol. 20, no. 8, pp. 865-880, 2000.

[5] E. Flaounas, S. Bastin, and S. Janicot, "Regional climate modelling of the 2006 West African monsoon: sensitivity to convection and planetary boundary layer parameterization using WRF," Climate Dynamics, vol. 5-6, pp. 1083-1105, 2011.

[6] N. Vigaud, P. Roucou, B. Fontaine, S. Sijikumar, and S. Tyteca, "WRF/ARPEGE-CLIMAT simulated climate trends over West Africa," Climate Dynamics, vol. 36, no. 5-6, pp. 925-944, 2011.

[7] J. Liu, M. Bray, and D. Han, "A study on WRF radar data assimilation for hydrological rainfall prediction," Hydrology and Earth System Sciences, vol. 17, no. 8, pp. 3095-3110, 2013.

[8] X. Yuan, X.-Z. Liang, and E. F. Wood, "WRF ensemble downscaling seasonal forecasts of China winter precipitation during 1982-2008," Climate Dynamics, vol. 39, no. 7-8, pp. 2041-2058, 2012.

[9] E. Díez, C. Primo, J. A. García-Moya, J. M. Gutiérrez, and B. Orfila, "Statistical and dynamical downscaling of precipitation over Spain from DEMETER seasonal forecasts," Tellus Series A: Dynamic Meteorology and Oceanography, vol. 57, no. 3, pp. 409423, 2005.

[10] S.-Y. Hong, J. Dudhia, and S.-H. Chen, "A revised approach to ice microphysical processes for the bulk parameterization of 
clouds and precipitation," Monthly Weather Review, vol. 132, no. 1, pp. 103-120, 2004.

[11] S. Y. Hong, K. S. S. Lim, Y. H. Lee et al., "Evaluation of the WRF double-moment 6-class microphysics scheme for precipitating convection," Advances in Meteorology, vol. 2010, Article ID 707253, 10 pages, 2010.

[12] K. A. Emanuel and D. J. Raymond, The Representation of Cumulus Convection in Numerical Models, American Meteorological Society, Boston, MA, USA, 1993.

[13] Z. I. Janjić, "Comments on "Development and Evaluation of a Convection Scheme for Use in Climate Models"," Journal of the Atmospheric Sciences, vol. 57, no. 21, pp. 3686-3686, 2000.

[14] G. A. Grell and D. Dévényi, "A generalized approach to parameterizing convection combining ensemble and data assimilation techniques," Geophysical Research Letters, vol. 29, no. 14, pp. 381-38-4, 2002.

[15] S. Hong, Y. Noh, and J. Dudhia, "A new vertical diffusion package with an explicit treatment of entrainment processes," Monthly Weather Review, vol. 134, no. 9, pp. 2318-2341, 2006.

[16] J. E. Pleim, "A combined local and nonlocal closure model for the atmospheric boundary layer. Part I. Model description and testing," Journal of Applied Meteorology and Climatology, vol. 46, no. 9, pp. 1383-1395, 2007.

[17] J. E. Pleim, "A combined local and nonlocal closure model for the atmospheric boundary layer. Part II: application and evaluation in a mesoscale meteorological model," Journal of Applied Meteorology and Climatology, vol. 46, no. 9, pp. 13961409, 2007.

[18] F. Chen and J. Dudhia, "Coupling an advanced land surface-hydrology model with the Penn State-NCAR MM5 modeling system. Part II: preliminary model validation," Monthly Weather Review, vol. 129, no. 4, pp. 587-604, 2001.

[19] P. A. Jiménez, J. Dudhia, J. F. González-Rouco, J. Navarro, J. P. Montávez, and E. García-Bustamante, "A revised scheme for the WRF surface layer formulation," Monthly Weather Review, vol. 140, no. 3, pp. 898-918, 2012.

[20] M. J. Iacono, J. S. Delamere, E. J. Mlawer, M. W. Shephard, S. A. Clough, and W. D. Collins, "Radiative forcing by long-lived greenhouse gases: calculations with the AER radiative transfer models," Journal of Geophysical Research: Atmospheres, vol. 113, no. 13, Article ID D13103, 2008.

[21] J. Dudhia, "Numerical study of convection observed during the Winter Monsoon Experiment using a mesoscale twodimensional model," Journal of the Atmospheric Sciences, vol. 46, no. 20, pp. 3077-3107, 1989.

[22] D. P. Dee, S. M. Uppala, A. J. Simmons et al., “The ERA-Interim reanalysis: configuration and performance of the data assimilation system," Quarterly Journal of the Royal Meteorological Society, vol. 137, no. 656, pp. 553-597, 2011.

[23] W. C. Skamarock, J. B. Klemp, J. Dudhia, D. O. Gill, D. M. Barker, and M. G. Duda, A description of the Advanced Research WRF Version 3, NCAR technical note, Mesoscale and Microscale Meteorology Division, National Center for Atmospheric Research, Boulder, Colo, USA, 2008.

[24] D. Maraun, F. Wetterhall, A. M. Ireson et al., "Precipitation downscaling under climate change: Recent developments to bridge the gap between dynamical models and the end user," Reviews of Geophysics, vol. 48, no. 3, pp. 1-34, 2010.

[25] T. Annor, B. Lamptey, S. Wagner et al., "High-resolution longterm WRF climate simulations over Volta Basin. Part 1: validation analysis for temperature and precipitation," Theoretical and Applied Climatology, pp. 1-21, 2017.
[26] F. Nkrumah, N. A. Klutse, D. C. Adukpo et al., "Rainfall Variability over Ghana: Model versus Rain Gauge Observation," International Journal of Geosciences, vol. 05, no. 07, pp. 673-683, 2014.

[27] G. Gu and R. F. Adler, "Seasonal evolution and variability associated with the West African monsoon system," Journal of Climate, vol. 17, no. 17, pp. 3364-3377, 2004.

[28] S. Janicot, A. Harzallah, B. Fontaine, and V. Moron, "West African monsoon dynamics and eastern equatorial Atlantic and Pacific SST anomalies (1970-88)," Journal of Climate, vol. 11, no. 8, pp. 1874-1882, 1998.

[29] J. B. Omotosho, "Pre-rainy season moisture build-up and storm precipitation delivery in the West African Sahel," International Journal of Climatology, vol. 28, no. 7, pp. 937-946, 2008.

[30] U. Schneider, M. Ziese, A. Becker, A. Meyer-Christoffer, and P. Finger, Globalprecipitation analysis products of the GPCC, Global Precipitation Climatology Centre (GPCC), Deutscher Wetterdienst, Offenbach a. M., Germany, 2015.

[31] H. Paeth, N. M. J. Hall, M. A. Gaertner et al., "Progress in regional downscaling of west African precipitation," Atmospheric Science Letters, vol. 12, no. 1, pp. 75-82, 2011.

[32] S. E. Nicholson, B. Some, J. McCollum et al., "Validation of TRMM and other rainfall estimates with a high-density gauge dataset for West Africa. Part I: Validation of GPCC rainfall product and Pre-TRMM satellite and blended products," Journal of Applied Meteorology and Climatology, vol. 42, no. 10, pp. 1337-1354, 2003.

[33] A. J. Koutsouris, D. Chen, and S. W. Lyon, "Comparing global precipitation data sets in eastern Africa: A case study of Kilombero Valley, Tanzania," International Journal of Climatology, vol. 36, no. 4, pp. 2000-2014, 2016.

[34] N. A. B. Klutse, M. B. Sylla, I. Diallo et al., "Daily characteristics of West African summer monsoon precipitation in CORDEX simulations," Theoretical and Applied Climatology, vol. 123, no. 1-2, pp. 369-386, 2016.

[35] E. K. Vizy and K. H. Cook, “Tropical storm development from African easterly waves in the Eastern Atlantic: A comparison of two successive waves using a regional model as part of NASA AMMA 2006," Journal of the Atmospheric Sciences, vol. 66, no. 11, pp. 3313-3334, 2009.

[36] E. Noble, L. M. Druyan, and M. Fulakeza, "The sensitivity of WRF daily summertime simulations over West Africa to alternative parameterizations. Part I: African wave circulation," Monthly Weather Review, vol. 142, no. 4, pp. 1588-1608, 2014.

[37] A. W. Ireland, "The Little Dry Season of Southern Nigeria," Technical Note no. 24, of the Nigerian Meteorological Service, Nigeria, 1962. 

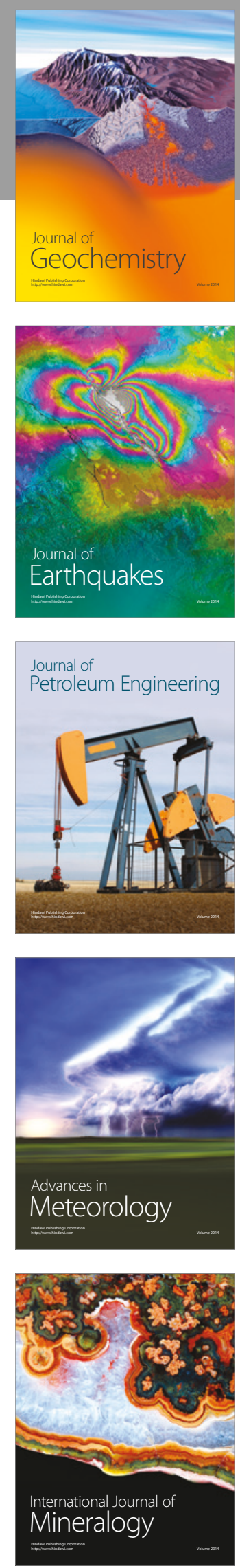
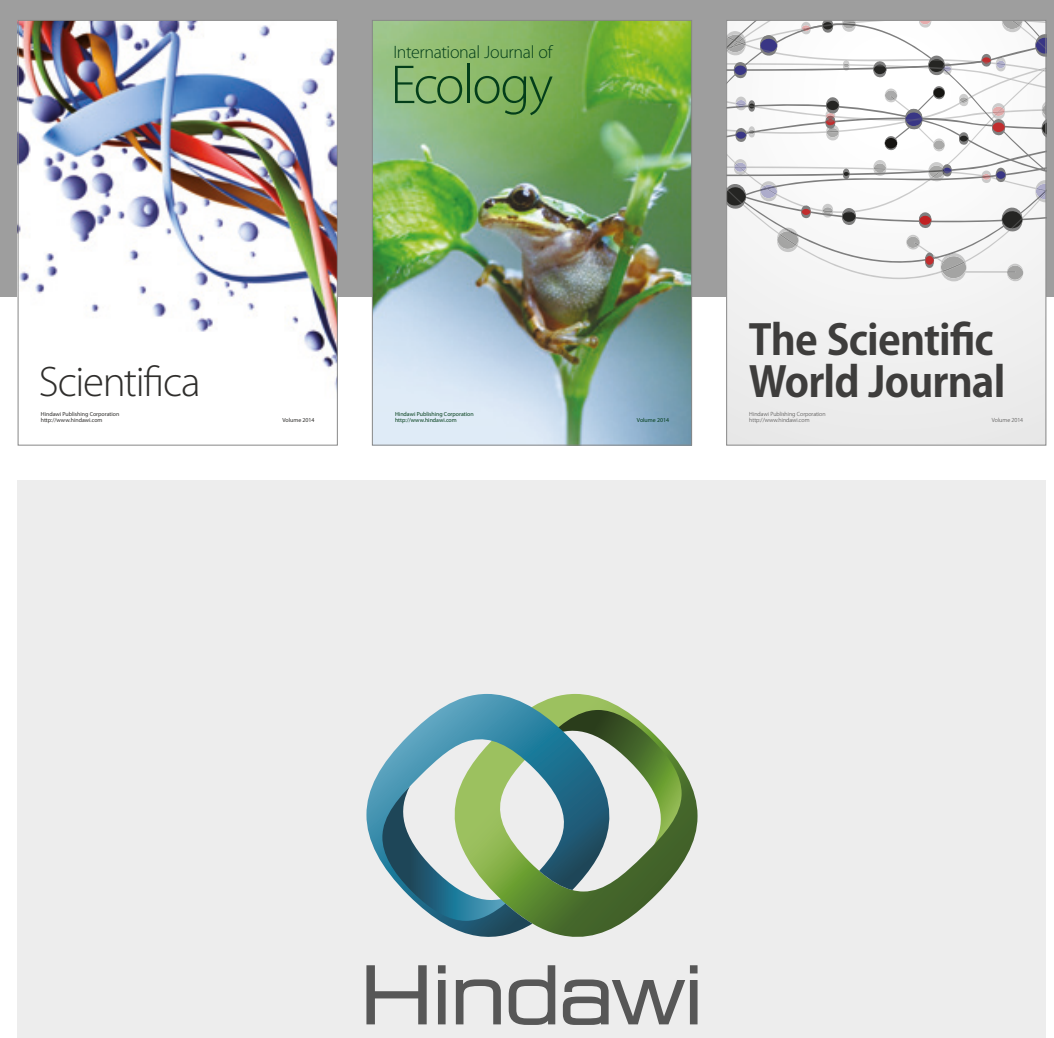

Submit your manuscripts at

https://www.hindawi.com
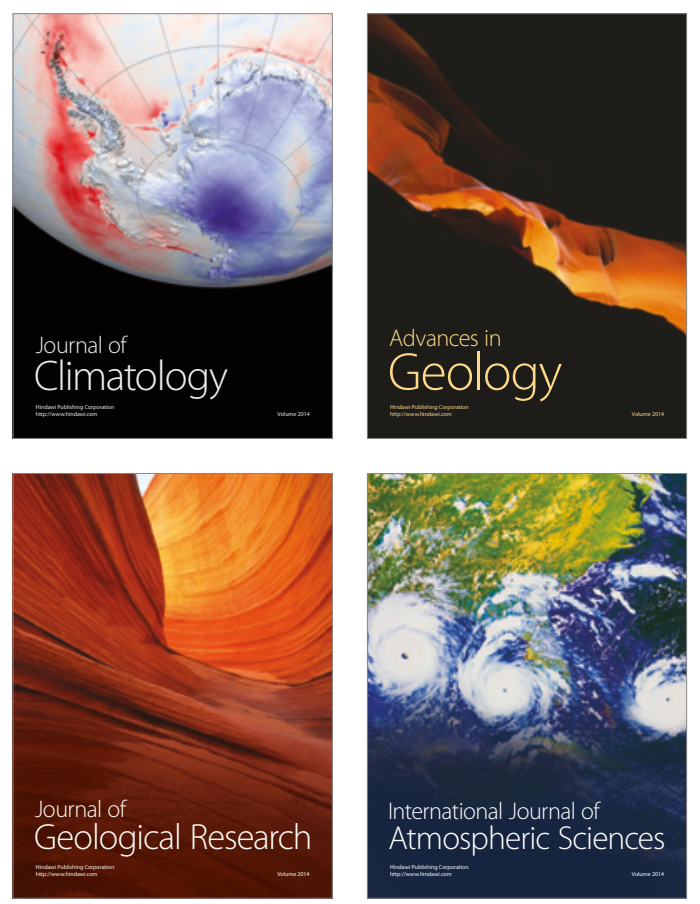

The Scientific

World Journal
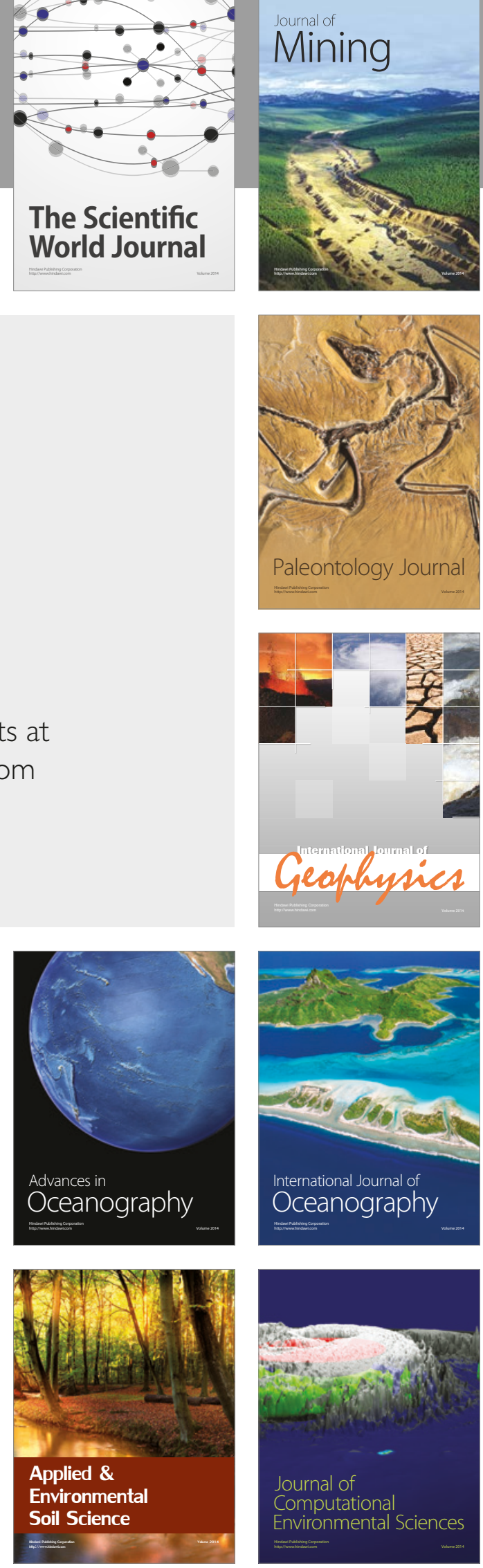